\title{
Up-regulation of Connective Tissue Growth Factor in Hyperoxia-Induced Lung Fibrosis
}

\author{
CHUNG-MING CHEN, LENG-FANG WANG, HSIU-CHU CHOU, YAW-DONG LANG, AND YI-PING LAI
}

Department of Pediatrics [C.-M.C.], Taipei Medical University Hospital; Department of Biochemistry [L.-F.W.], Department of Anatomy [H.-C.C.], Graduate Institute of Medical Sciences [Y.-D.L.], College of Medicine; School of Nutrition and Health Science [Y.-P.L.], Taipei Medical University, Taipei 110, Taiwan

\begin{abstract}
Pulmonary oxygen toxicity plays an important role in the lung injury process that leads to the development of bronchopulmonary dysplasia. Connective tissue growth factor (CTGF) is a fibroblast mitogen and promoter of collagen deposition. We investigated the effects of postnatal hyperoxia on lung collagen and CTGF expression in rats. Rat pups were exposed to $7 \mathrm{~d}$ of $>95 \% \mathrm{O}_{2}$ and a further $3 \mathrm{wk}$ of $60 \% \quad \mathrm{O}_{2}$. CTGF mRNA and protein expression increased after hyperoxia treatment, and the values were significantly higher in hyperoxia-exposed rats on postnatal $d 7$ and 14. Lung collagen levels increased as rats aged, and the values were comparable between room air-exposed and hyperoxia-exposed rats on postnatal $\mathrm{d} 7$ and 14 and were significantly higher in hyperoxia-exposed rats on postnatal d 21 and 28. Increases in CTGF mRNA and protein expressions preceded the onset of increased lung collagen. These data demonstrate that CTGF is up-regulated at time points preceding the fibrotic phase of the lung injury adding credence to the hypothesis that CTGF seems to be involved in the pathogenesis of hyperoxia-induced lung fibrosis and an anti-CTGF strategy might attenuate hyperoxia-induced lung fibrosis. (Pediatr Res 62: 128-133, 2007)
\end{abstract}

$\mathrm{T}$ The pathogenesis of BPD is multifactorial, and pulmonary oxygen toxicity is considered to play an important role in the lung injury process that leads to the development of BPD (1). BPD is characterized by decreased alveolar and capillary development and subsequent fibrosis (2). Despite recent improvements in preventing respiratory distress syndrome in preterm infants, BPD remains a major cause of morbidity and mortality during the first year of life, and many infants experience significant respiratory morbidity, including increased airway reactivity and development of obstructive airway disease throughout childhood (3). Some abnormal lung functions may persist into adulthood (4). Pulmonary fibrosis is characterized by the excessive production of ECM (5). Collagen is the major ECM component of the lungs and is vital for maintaining the normal lung architecture (6). The increase in collagen is correlated with changes in the viscoelastic behavior and impaired lung function in lung fibrosis $(7,8)$. However, no effective therapy is currently clinically available to prevent long-term pulmonary sequelae of BPD.

Received November 2, 2006; accepted March 7, 2007.

Correspondence: Chung-Ming Chen, M.D., Ph.D., Department of Pediatrics, Taipei Medical University Hospital, $252 \mathrm{Wu}$ Hsing Street, Taipei 110, Taiwan; e-mail: cmchen@tmu.edu.tw
The accumulation of connective tissue in lung tissue is controlled by various growth factors. Much attention has previously been focused on transforming growth factor- $\beta 1$ (TGF- $\beta 1$ ), a known regulator of collagen synthesis (9). Recently, a new growth factor, termed CTGF, which functions as a downstream mediator of TGF- $\beta 1$, was found (10). CTGF, a member of the CCN (CTGF, Cyr61/Cef10, Nov) family, is a cysteine-rich, heparin-binding, 349-amino acid polypeptide (11). CTGF was originally identified in conditioned media from human umbilical vein endothelial cells and mice fibroblasts; it is implicated in fibroblast proliferation, cellular adhesion, angiogenesis, and ECM synthesis. Since its discovery in 1991, accumulating evidence has indicated that CTGF is an attractive target for antifibrotic therapy because inhibition of CTGF might block the profibrotic effects of TGF- $\beta 1$ (12). Prolonged exposure of neonatal mice to hyperoxia resulted in decreased alveolar septation, increased terminal air space size, and increased lung fibrosis, which are very similar to human BPD (13). We postulated that if CTGF expression plays an important role in lung fibrogenesis, it would increase during development of hyperoxia-induced lung fibrosis. To test this hypothesis, we exposed neonatal rats to hyperoxia at birth and examined CTGF expression at postnatal 4 wk. The aim of this study was to investigate the effects of postnatal hyperoxic exposure on lung CTGF expression and lung morphology.

\section{MATERIALS AND METHODS}

Animals. The study was performed in accordance with guidelines provided and approved by the Animal Care Use Committee of Taipei Medical University. Time-dated pregnant SpragueDawley rats were housed in individual cages with free access to laboratory food and water ad libitum, kept on a 12:12-h light-dark cycle, and allowed to deliver vaginally at term.

Exposure to hyperoxia. Within $12 \mathrm{~h}$ of birth, litters were separated from their mothers, pooled before being randomly redistributed to the newly delivered mother and exposed to $>95 \% \mathrm{O}_{2}$ or room air. Nursing mothers were rotated between oxygen-exposed and room-air litters every $24 \mathrm{~h}$ to avoid oxygen toxicity in the mothers and to eliminate maternal effects between groups. Oxygen exposures was carried out in

Abbreviations: BPD, bronchopulmonary dysplasia; CT, threshold cycle; CTGF, connective tissue growth factor; ECM, extracellular matrix 
a transparent $60 \times 50 \times 40$-cm Plexiglas chamber into which oxygen was continuously delivered at $4 \mathrm{~L} / \mathrm{min}$ and oxygen levels were monitored with a Pro:ox Model 110 monitor (BioSpherix, Redfield, NY) and humidity was checked daily and the value was $60-80 \%$. Litters were exposed to $7 \mathrm{~d}$ of $>95 \% \mathrm{O}_{2}$ and then were allowed to recover from the acute injury in a continuing environment of moderate hyperoxia $\left(60 \% \mathrm{O}_{2}\right)$ for a further $3 \mathrm{wk}$ (4 wk of total hyperoxia). Body and lung weights were recorded at the time of sacrifice. Lung tissues from room air- and hyperoxia-exposed pups were harvested on postnatal d 7, 14, 21, and 28 .

CTGF mRNA expression by real-time PCR. Lung tissue was ground into a powder in liquid nitrogen, and CTGF gene expression was measured using a real-time PCR. Total RNA was extracted using the TRIzol Reagent (Invitrogen Life Technologies, Paisley, UK). Reverse transcription was performed on $1 \mu \mathrm{g}$ of RNA with oligo-dT primers and avian myeloblastosis virus reverse transcriptase (Roche, Indianapolis, IN). Primer sequences for sybr green real-time PCR included: CTGF sense 5'-CCGACTGGAAGACACATTTG3', antisense 5'-CCAGCCTGCAGAAGGTATTG-3'; 18S rRNA sense 5' $5^{\prime}$-CGCCGCTAGAGGTGAAATTC-3', antisense $5^{\prime}$-CCAGTCGGCATCGTTTATGG-3'. Gene expression was quantitatively analyzed using the comparative $\mathrm{CT}$ $(\Delta \mathrm{CT})$ method, in which $\mathrm{CT}$ is the threshold cycle number (the minimum number of cycles needed before the product can be detected). The arithmetic formula for the $\Delta \mathrm{CT}$ method is the difference in threshold cycles for a target (CTGF) and an endogenous reference (the 18S rRNA housekeeping gene). The amount of target normalized to an endogenous reference and relative to a calibration normalized to an endogenous reference is given by $2 \Delta \Delta \mathrm{CT}$.

Western blot analysis. Lung tissues were homogenized in ice-cold buffer containing $50 \mathrm{mM}$ Tris. $\mathrm{HCl}(\mathrm{pH}$ 7.5), $1 \mathrm{mM}$ EGTA, $1 \mathrm{mM}$ EDTA, and protease inhibitor cocktail (complete minitablets; Roche, Mannheim, Germany). The samples were sonicated and then centrifuged at $500 \mathrm{~g}$ for $20 \mathrm{~min}$ at $4^{\circ} \mathrm{C}$ to remove cellular debris. Proteins $(30 \mu \mathrm{g})$ were resolved on $12 \%$ SDS-PAGE under reducing conditions and electroblotted to a polyvinylidene diflouride membrane (Immobilon ${ }^{\mathrm{P}}$, Millipore, Bedford, MA). After blocking with 5\% nonfat dry milk, the membranes were incubated with anti-CTGF (1:2000, Abcam, Cambridge, UK) or anti- $\beta$-actin (1:20,000; Sigma Chemical Co.-Aldrich, St. Louis, MO) and subsequently with horseradish peroxidase-conjugated goat anti-rabbit IgG or anti-mouse $\operatorname{IgG}$ (Pierce Biotechnology, Rockford, IL). Protein bands were detected using SuperSignal Substrate from Pierce. Densitometric analysis was performed to measure the intensity of CTGF and $\beta$-actin bands using AIDA software. (Advanced Image Data Analyzer, 2.11; Raytest Izotopenmessgeraete, Straubenhardt, Germany).

Measurement of collagen in lung tissue. Lung collagen was determined by assaying total soluble collagen using the Sircol collagen assay kit (Biocolor Ltd., Newton Abbey, UK) according to the manufacturer's instructions. Briefly, lungs were homogenized in $5 \mathrm{~mL}$ of $0.5 \mathrm{M}$ acetic acid containing 1 mg pepsin (Sigma Chemical Co., St. Louis, MO) per $10 \mathrm{mg}$ tissue residue. Each sample was incubated for $24 \mathrm{~h}$ at $4^{\circ} \mathrm{C}$ with stirring. After centrifugation, $100 \mu \mathrm{L}$ of each supernatant was assayed. One milliliter of Sircol dye reagent that specifically binds to collagen was then added to each sample and mixed for $30 \mathrm{~min}$. After centrifugation, the pellet was suspended in 1 $\mathrm{mL}$ of alkali reagent $(0.5 \mathrm{M} \mathrm{NaOH})$ included in the kit, and the OD was evaluated at $540 \mathrm{~nm}$ with a spectrophotometer. Values in the test samples were compared with values obtained with collagen standard solutions provided by the manufacturer that were used to construct a standard curve.

Histologic examination. Animals were killed by an intraperitoneal injection of pentobarbital sodium and were exsanguinated by aortic transection. The lungs were placed in $4 \%$ paraformaldehyde and washed in PBS and serially dehydrated in increasing concentrations of ethanol before being embedded in paraffin. To standardize the analyses, lung sections were taken from central areas of the right lower lobe. Fivemicrometer tissue sections were stained with hematoxylin and eosin (H\&E), examined by light microscopy, and assessed for the presence of hemorrhage, intra-alveolar edema, inflammatory cell infiltration, and fibrosis.

Immunohistochemistry. Immunohistochemical staining for CTGF was performed on paraffin sections with immunoperoxidase visualization. After deparaffinization in xylene and rehydration in an alcohol series, sections were first preincubated for $1 \mathrm{~h}$ at room temperature in 0.1 M PBS containing $10 \%$ normal goat serum and $0.3 \% \mathrm{H}_{2} \mathrm{O}_{2}$ to block endogenous peroxidase activity and nonspecific binding of antibody before being incubated for $20 \mathrm{~h}$ at $4^{\circ} \mathrm{C}$ with a primary rabbit antibody against CTGF (1:500, Abcam, Cambridge, UK). Sections were then treated for $1 \mathrm{~h}$ at room temperature with biotinylated goat anti-rabbit IgG (1:200; Vector Laboratories, Burlingame, CA). This is followed by the reaction with the reagents from an $\mathrm{ABC}$ kit (Avidin-Biotin Complex, Vector Laboratories) as the manufacturer's recommendations, and the reaction products were visualized by 3,3 diaminobenzidine and $0.003 \% \mathrm{H}_{2} \mathrm{O}_{2}$ in $0.5 \mathrm{M}$ Tris $\mathrm{HCl}$ before the sections were mounted on gelatincoated slides using Permount (Fisher Scientific, Pittsburgh, PA).

In situ detection of apoptotic cells in epithelial cells. Terminal deoxynucleotidyl transferase (TdT)-mediated dUTP nick end labeling (TUNEL) was carried out to detect apoptotic DNA damage using the Apo-Brdu-IHC In Situ DNA fragmentation assay kit (BioVision, Mountain View, CA). Positive staining was indicated as brown and background staining was blue-green. Apoptosis was semiquantitatively measured by counting TUNEL-positive and -negative cells of the alveolar wall. A pathologist who was blinded to the treatment group systemically and randomly counted the cells until reaching a total number of 8000 alveolar wall cells. Values were expressed as the percent of apoptotic cells.

Statistical analysis. Results are presented as the mean \pm SEM. Analysis of difference among multiple groups was carried out by one-way ANOVA and significance was determined using Bonferroni's correction for multiple comparisons and $t$ test for two groups. Differences were considered significant at $p<0.05$.

\section{RESULTS}

Body weight, lung weight, and the lung/body weight ratio (\%). Effects of hyperoxia on body weight, lung weight, and 
Table 1. Body weight, lung weight, and the lung/body weight ratio in room air-and hyperoxia-exposed rats

\begin{tabular}{lccccc}
\hline Treatment & No. & Postnatal age $(\mathrm{d})$ & Body weight $(\mathrm{g})$ & Lung weight $(\mathrm{g})$ & Lung/body weight $(\%)$ \\
\hline Room air & 8 & 7 & $13.34 \pm 0.30$ & $0.24 \pm 0.01$ & $1.82 \pm 0.05$ \\
Hyperoxia & 6 & 7 & $8.71 \pm 0.58 \S$ & $0.14 \pm 0.01 \S$ & $1.57 \pm 0.05 * *$ \\
Room air & 8 & 14 & $21.71 \pm 1.02$ & $0.30 \pm 0.02$ & $1.38 \pm 0.06$ \\
Hyperoxia & 7 & 14 & $15.67 \pm 0.50 \S$ & $0.25 \pm 0.01$ & $1.63 \pm 0.05 * *$ \\
Room air & 8 & 21 & $30.18 \pm 1.48$ & $0.31 \pm 0.01$ & $1.00 \pm 0.01$ \\
Hyperoxia & 6 & 21 & $19.94 \pm 1.22 \S$ & $0.32 \pm 0.02$ & $1.49 \pm 0.10^{* *}$ \\
Room air & 8 & 28 & $43.66 \pm 2.49$ & $0.43 \pm 0.02$ & $0.99 \pm 0.06$ \\
Hyperoxia & 7 & 28 & $36.29 \pm 2.37$ & $0.37 \pm 0.02$ & $1.01 \pm 0.04$ \\
\hline
\end{tabular}

Values are the mean $\pm \mathrm{SEM}$; ** $p<0.01, \S p<0.001$, compared with room air-exposed rats at each time point.

the lung/body weight ratio (\%) are presented in Table 1. Rats exposed to hyperoxia exhibited significantly lower body weights when compared with room-air controls on postnatal d 7, 14, and 21. Lung weights were significantly lower in hyperoxia-exposed rats on postnatal $\mathrm{d} 7$, and values were comparable between room air- and hyperoxia-exposed rats on postnatal d 14, 21, and 28. The lung/body weight ratio was significantly smaller in hyperoxia-exposed rats on postnatal d 7 , and the values became significantly greater in room airexposed rats on postnatal d 14 and 21 .

CTGF mRNA expression. The time-course effects of hyperoxia on lung CTGF mRNA expression from postnatal d 7 to 28 are presented in Figure 1. CTGF mRNA expression significantly increased 2-fold on postnatal d 7 and 14 in hyperoxiaexposed rats relative to room air-exposed rats. CTGF mRNA expression then decreased, and the values were comparable between room air- and hyperoxia-exposed rats on postnatal d 21 and 28.

Western blot analysis of CTGF. CTGF protein levels increased after hyperoxia treatment (Fig. 2), and the mean value was significantly greater in hyperoxia-exposed rats on postnatal d 7 when compared with rats on postnatal d 21 and 28, then the mean value reached a peak and significantly greater in hyperoxia-exposed rats on postnatal d 14 when compared with all other groups.

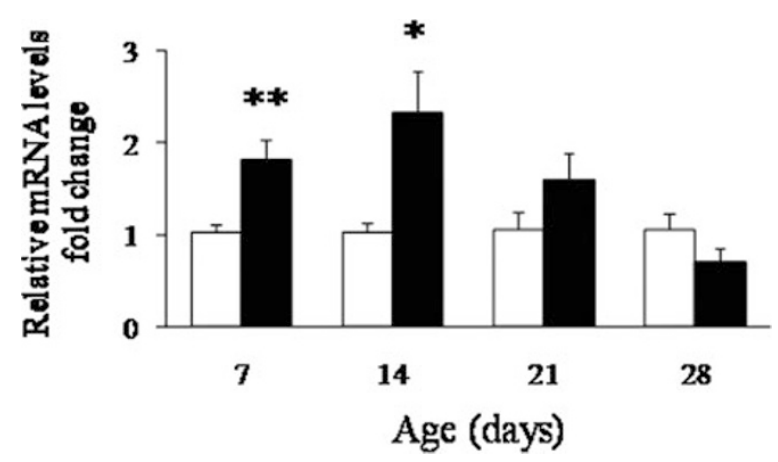

Figure 1. Time-course effects of hyperoxia on CTGF mRNA expression in room air (open bars) and hyperoxia (solid bars) - exposed rats from postnatal d 7 to 28. Total RNA from the lung was extracted, and the mRNA encoding the CTGF gene was examined using real-time PCR. The expression levels were normalized to 18S RNA and are reported as fold-change relative to room air-exposed animals. Bars are means \pm SEM $(n=5)$. CTGF mRNA expression increased after hyperoxic treatment, and the values were significantly higher in hyperoxia-exposed rats on postnatal d 7 and 14 when compared with the room air-exposed group $\left(* p<0.05\right.$ and $\left.{ }^{* *} p<0.01\right)$, then the value decreased after postnatal d 21 .
Lung collagen level. Lung collagen levels increased as rats aged, and the values were comparable between room air- and hyperoxia-exposed rats on postnatal d 7 and 14 and were significantly higher in hyperoxia-exposed rats when compared with room air-exposed rats on postnatal d 21 and 28 (Fig. 3).

Immunohistochemistry. The CTGF protein was localized in fibroblasts in the alveolar interstitium (Fig. 4). The cells contained CTGF immunoreactivity showed typical fibroblast morphology, many being spindle-shaped. Low CTGF immunoreactivity was detected in room-air controls at all 4 postnatal weeks. In hyperoxia-exposed rats, CTGF immunoreactivity increased on postnatal d 7 and 14 when compared with room-air controls. After 2 wk of hyperoxia, CTGF expression decreased on postnatal d 21 and remained low on postnatal d 28.

Histology. Representative lung sections from room air- and hyperoxia-exposed rats are presented in Figure 5. On postnatal d 7, the lungs of hyperoxia-exposed rats contained large thin-walled air spaces when compared with room air-exposed rats. On postnatal d 14, the lungs of hyperoxia-exposed rats

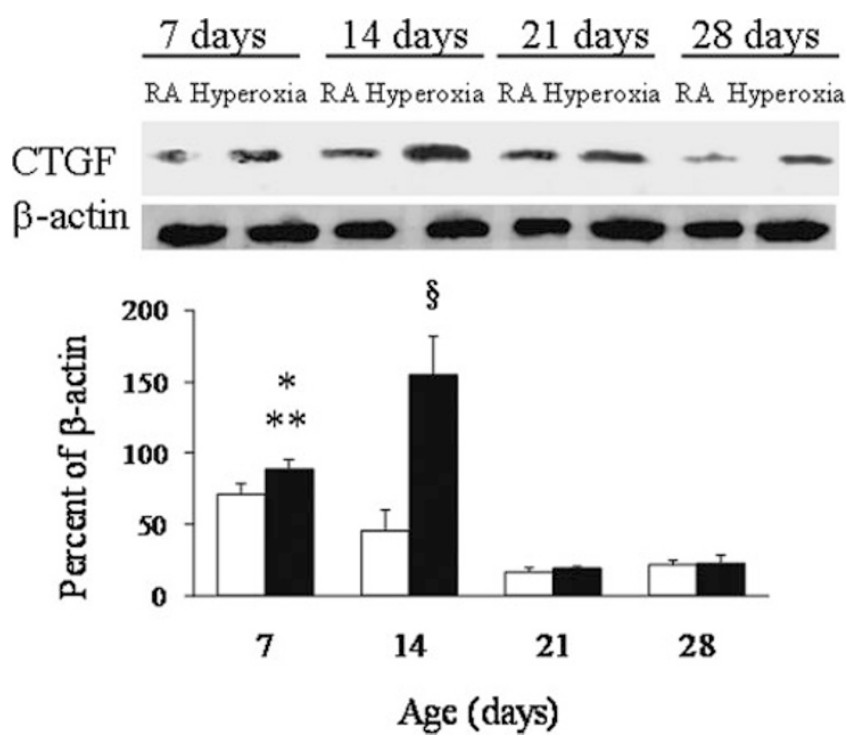

Figure 2. Representative Western blots and quantitative data determined by densitometry for the CTGF protein in room air (RA, open bars) and hyperoxia (solid bars) -exposed rat lungs. Data were normalized to $\beta$-actin for each animal. Bars are means \pm SEM $(n=4)$. CTGF protein levels increased after hyperoxia treatment, and the mean value was significantly greater in hyperoxia-exposed rats on postnatal $\mathrm{d} 7$ when compared with rats on postnatal d 21 $(* * p<0.01)$ and $28(* p<0.05)$, then the mean value reached a peak and significantly greater in hyperoxia-exposed rats on postnatal d 14 when compared with all other groups $(\$ p<0.001)$. 


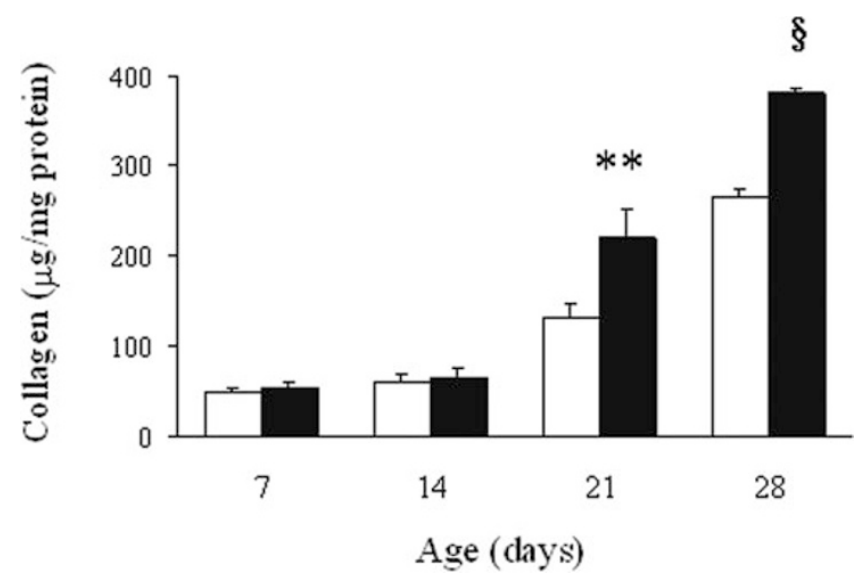

Figure 3. Lung collagen levels in room air (open bars) and hyperoxia (solid bars $)$-exposed rats. Bars are means $\pm \operatorname{SEM}(n=4)$. Lung collagen levels increased as rats aged, and the values were comparable between room air- and hyperoxia-exposed rats on postnatal d 7 and 14 and were significantly higher in hyperoxia-exposed rats on postnatal $\mathrm{d} 21$ and 28 when compared with room air-exposed rats $(* * p<0.01, \S p<0.001)$.

had larger air spaces, fewer secondary septa, and wide interstitium with inflammatory cell recruitment. On postnatal d 21 and 28, the lungs of hyperoxia-exposed rats contained larger air spaces and thicker interstitium with fibrosis. In the TUNEL assay, hyperoxia-exposed rats exhibited higher apoptosis of alveolar wall cells, and most apoptosis occurred primarily along the alveolar surface of the peripheral airways (Fig. 6); semiquantitative counting of TUNEL-positive and -negative cells in the alveolar wall showed that the room-air controls had a steady percentage of apoptotic cells during the study period, whereas the hyperoxia-exposed groups had significantly higher apoptotic cells than did the room air-exposed groups on postnatal d 7, 14, 21, and 28 (Fig. 7). The percentage of apoptotic cells decreased as rats aged in the hyperoxiaexposed groups.

\section{DISCUSSION}

Our in vivo model showed that exposure of neonatal rats to hyperoxia caused apoptosis of alveolar wall cells and reduced alveolarization as demonstrated by the large thin-walled air spaces and increased CTGF expression in the first 2 postnatal weeks. Further prolonged exposure to a lower concentration of oxygen caused lung fibrosis as confirmed by the increased lung collagen levels in the third and fourth postnatal weeks. These phenomena are consistent with hyperoxia-induced lung injury $(14,15)$. The main findings of this study are that the development of hyperoxia-induced lung fibrosis was associated with increases in lung CTGF mRNA and protein expressions and that up-regulation of CTGF expression precedes the increase in lung collagen levels. These results suggest that CTGF seems to be involved in the pathogenesis of hyperoxia-induced lung fibrosis and an anti-CTGF strategy might attenuate lung fibrosis. Further investigation of the role of CTGF may offer new treatment strategies in hyperoxia-induced lung fibrosis.

Murine alveolar development begins on postnatal d 4 and saccular division is completed by postnatal d 14 (16). Bonikos and colleagues (17) demonstrated that neonatal mice exposed

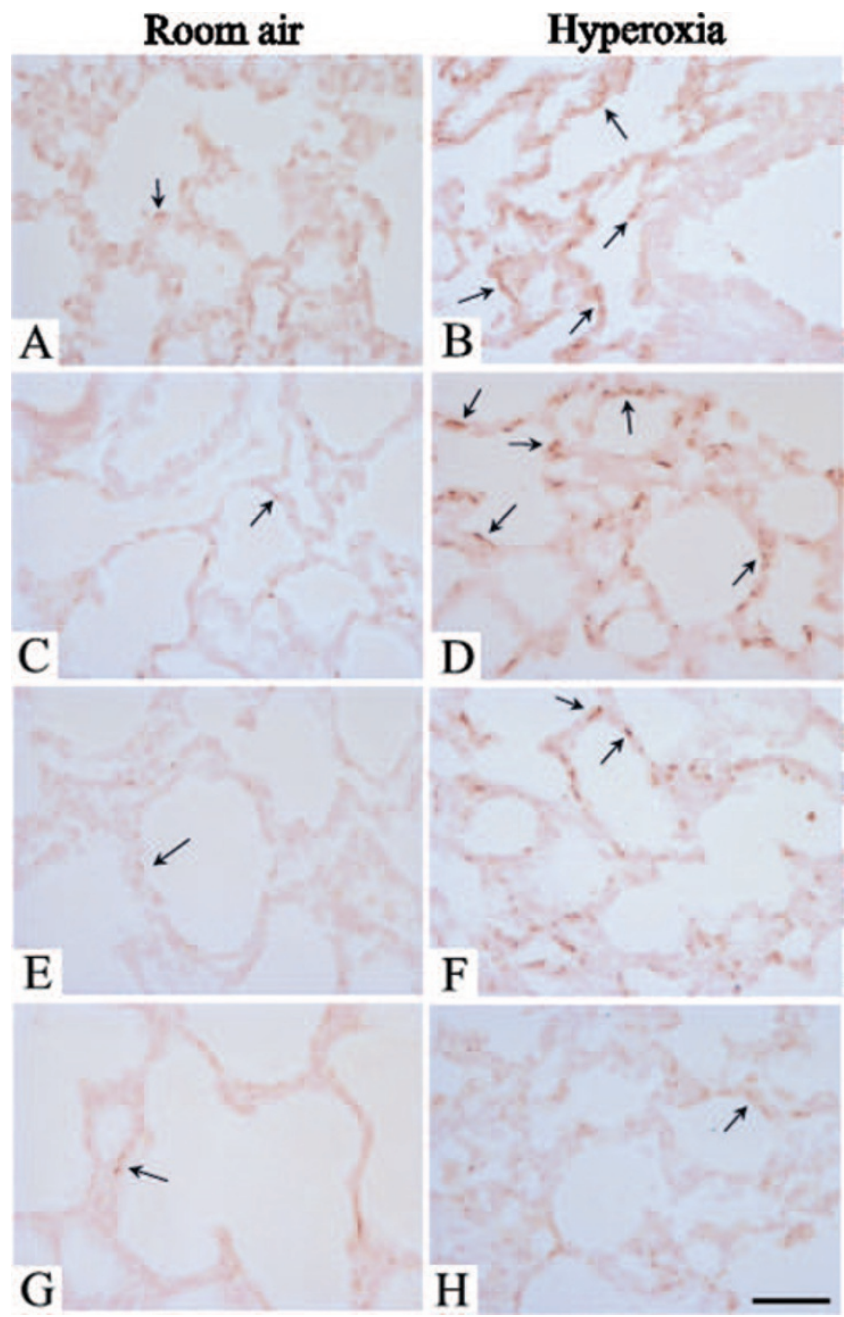

Figure 4. Immunohistochemical staining for CTGF in lung sections from room air- and hyperoxia-exposed rats $(\times 400)$. Positive staining is shown as brown (arrow). Shown are photomicrographs from postnatal $\mathrm{d} 7(A$ and $B), 14$ $(C$ and $D), 21(E$ and $F)$, and 28 ( $G$ and $H$ ) rats exposed to room air $(A, C, E$, $G)$ and hyperoxia $(B, D, F, H)$. The CTGF protein was localized in fibroblasts in the alveolar interstitium. Low CTGF immunoreactivity was detected in room-air controls at all 4 postnatal weeks. In hyperoxia-exposed rats, CTGF immunoreactivity increased on postnatal d 7 and 14 when compared with room-air controls. After 2 wk of hyperoxia, CTGF expression decreased on postnatal d 21 and remained low on postnatal d 28. Bar $=50 \mu \mathrm{m}$.

to prolonged hyperoxia develop chronic lung disease characterized by alveolar dysplasia and fibrosis. The newborn rat is particularly appropriate for studies of neonatal oxygen injury $(18,19)$. During the first 3 -wk period of hyperoxia in this study, the body weight of hyperoxia-exposed rats was reduced to $70 \%$ of that of the room-air controls. Lung weight was reduced to a lesser extent than body weight. In the present study, we found that hyperoxia-exposed rats exhibited significantly lower lung weight and lung/body weight ratio on postnatal $\mathrm{d} 7$ and higher lung/body weight ratios on postnatal d 14 and 21 . We speculated that these findings were due to arrested lung development on postnatal $\mathrm{d} 7$ and increased lung inflammation or lung water content on postnatal d 14 and 21 . Lung development and inflammation were further supported by prominent histologic alterations and lung water content could be estimated by the wet/dry lung weight ratio which is 


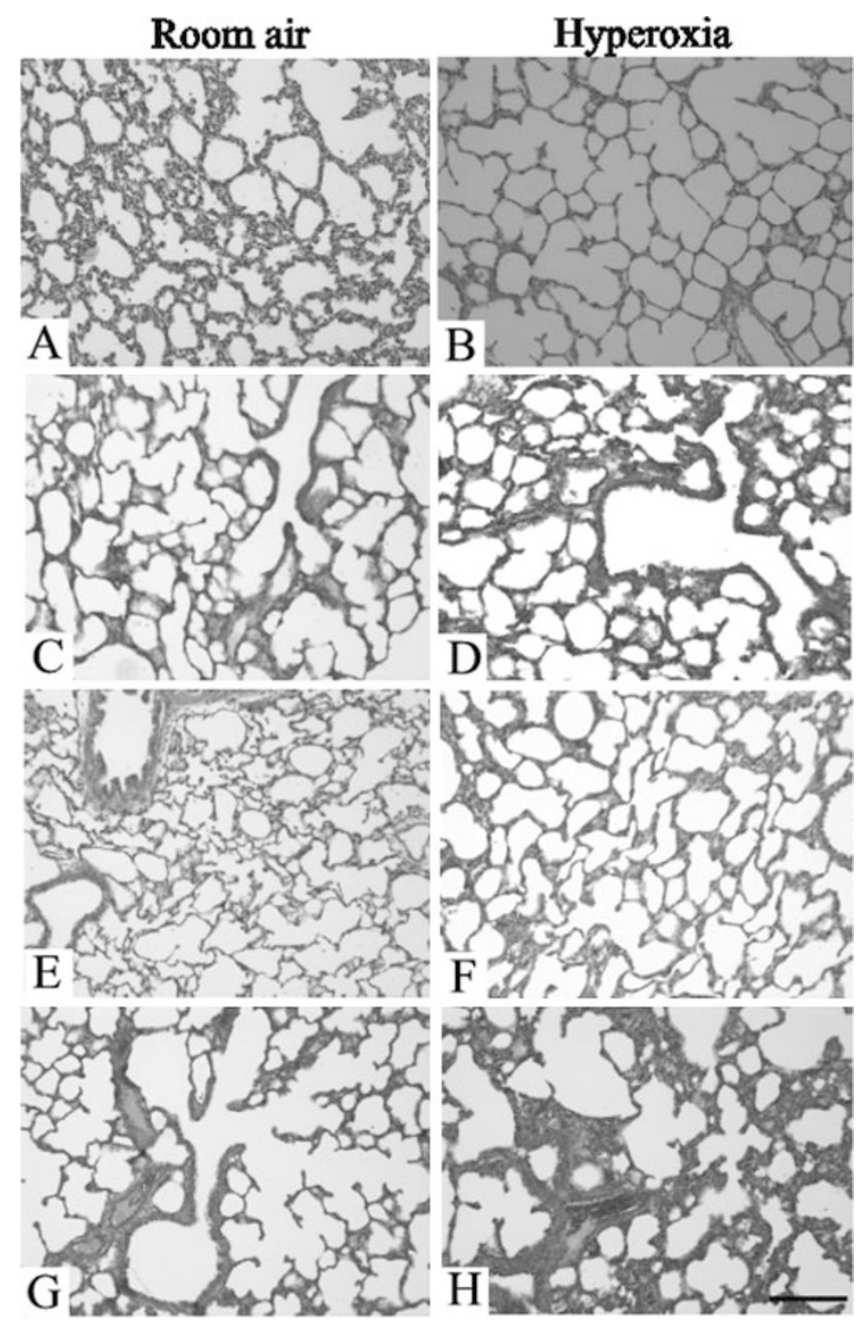

Figure 5. Morphology of representative lung sections from room air- and hyperoxia-exposed rats $(\mathrm{H} \& \mathrm{E}, \times 100)$. Shown are photomicrographs from postnatal d $7(A$ and $B), 14(C$ and $D), 21(E$ and $F)$, and $28(G$ and $H$ ) rats exposed to room air $(A, C, E, G)$ and hyperoxia $(B, D, F, H)$. While normal development and alveolarization can be seen in the room-air control group, the lungs of hyperoxia-exposed rats contained large thin-walled air spaces when compared with room air-exposed rats on postnatal d 7. On postnatal d 14 , hyperoxia-exposed rats contained larger air spaces, fewer secondary septa, and wider interstitium with inflammatory cell recruitment. On postnatal d 21 and 28, hyperoxia-exposed rats contained larger air space and a thicker interstitium with fibrosis. Bar $=200 \mu \mathrm{m}$.

a technique commonly used for assessment of pulmonary edema (20).

Therapy with hyperoxia is often needed to treat newborns with respiratory disorders. However, supplemental oxygen administered to newborn infants with respiratory failure can increase oxidant stress and lead to lung epithelial cell death. In this study, we chose this sort of hyperoxic exposure because our purpose was to establish a rat model of hyperoxia-induced lung fibrosis. During recovery from sublethal hyperoxia, lung cells may proliferate to replace terminally damaged cells and failure to impede this proliferation is associated with fibrosis $(21,22)$. Cell death by apoptosis has essential importance in both normal lung homeostasis and a variety of pathologic processes. Apoptosis appears to be the major mode of cell death when cells experience lethal oxidative insult from ex-

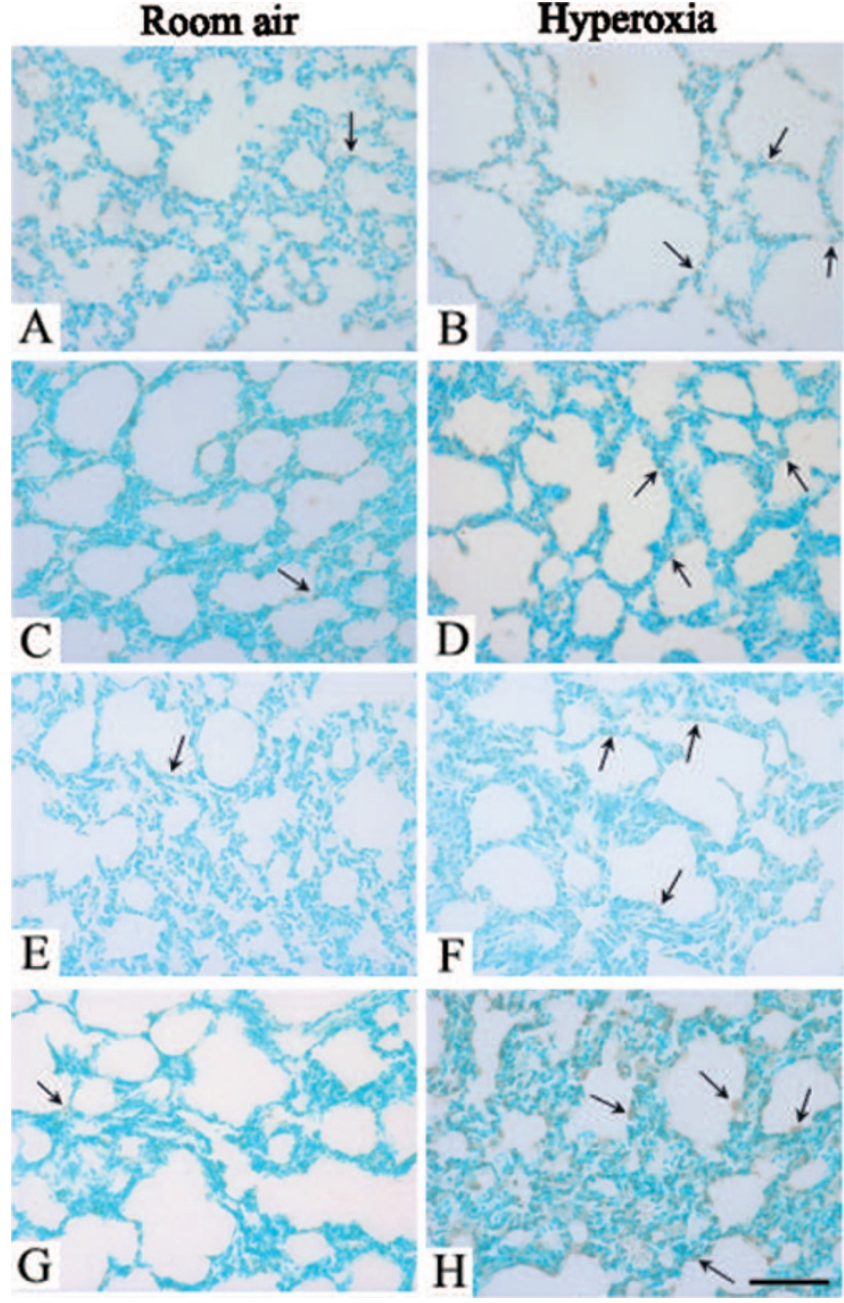

Figure 6. TUNEL staining of lung sections from room air- and hyperoxiaexposed rats $(\times 200)$. Positive staining is indicated by brown (arrow), and the background staining is blue-green. Shown are photomicrographs from postnatal $\mathrm{d} 7(A$ and $B), 14$ ( $C$ and $D), 21(E$ and $F$ ), and 28 ( $G$ and $H$ ) rats exposed to room air $(A, C, E, G)$ and hyperoxia $(B, D, F, H)$. Hyperoxia-exposed rats contained more apoptotic cells when compared with room air-exposed rats on postnatal $\mathrm{d} 7$, 14, 21, and 28. Bar $=100 \mu \mathrm{m}$.

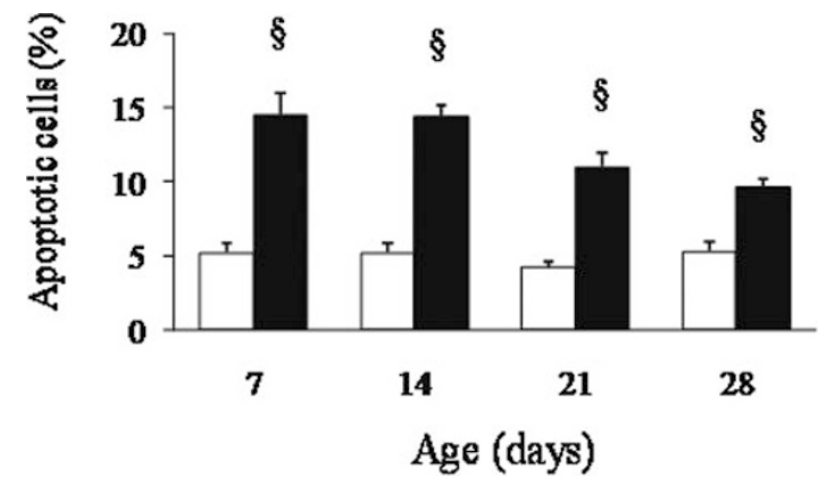

Figure 7. Semiquantitative measurement of apoptosis by counting TUNELpositive and -negative cells of the alveolar wall in room air (open bars) and hyperoxia (solid bars) -exposed rats. Bars are means \pm SEM $(n=6-8)$. Rats exposed to hyperoxia had significantly higher percentages of apoptotic cells than did the room air-exposed rats on postnatal d 7, 14, 21, and $28(\$ p<0.001)$.

posure to oxidants $(23,24)$. Alveolar epithelial cell apoptosis is an important feature of hyperoxia-induced lung injury in vivo and has been described in the early stages of BPD (25). 
Apoptosis of alveolar epithelial cells can interfere with the synthesis of surfactants and cause denuding of the alveolar capillary membrane, leading to the development of fibrosis and parenchyma remodeling. A number of studies support the concept that apoptosis of the alveolar epithelium initiates fibrotic foci and contributes to the pathogenesis of lung fibrosis. Adamson et al. (26) found that severe hyperoxia injury disturbs normal epithelial-fibroblast interactions and promotes fibrotic processes in the culture of mouse lung explants. These results were further supported by Hagimoto et al. (27), who found that intratracheal instillation of an antibody to activate the Fas receptor may induce apoptosis of alveolar epithelial cells and initiate a fibrotic response that was detectable $1 \mathrm{wk}$ later in mice. In this study, apoptotic activity was assessed by the TUNEL assay, which detects DNA fragmentation in tissue sections in situ. This may be considered a limitation of this study since TUNEL assay is not specific for apoptosis (28). However, the trends of apoptosis are principally similar to the results of Howlett et al. (29); therefore, this limitation is not likely to affect the applicability of our results.

Pulmonary fibrosis is a common response to various injuries to the lung and is characterized by abnormal lung physiology and by the excessive production of ECM replacing normal functional parenchyma (5). Collagen is the major ECM component of the lungs and is vital for maintaining the normal lung architecture (6). It is present in the adventitia of pulmonary arteries, the interstitium of the bronchial tree, the interlobular septa, the bronchial lamina propria, and the alveolar interstitium. The increase in collagen content is correlated with changes in the viscoelastic behavior of bleomycininduced lung fibrosis and impaired lung function in irradiation-induced lung fibrosis $(7,8)$. CTGF is a fibroblast mitogen and promoter of collagen deposition that acts downstream of TGF- $\beta 1$, particularly with respect to its profibrotic effects $(10,30)$. CTGF is an important player in the pathogenesis of various fibrotic disorders, including lung fibrosis and idiopathic pulmonary fibrosis (31-33). In this study, we found that increased CTGF mRNA and protein expression preceded the increase in collagen levels of lung tissues. Therefore, it is conceivable that inhibition of CTGF might block the profibrotic effects without affecting TGF- $\beta$ 's antiproliferative and immunosuppressive effects (12). Because CTGF can enhance collagen type I expression in fibroblasts (34), CTGF may be a new target molecule in the pathogenesis and progression of hyperoxia-induced lung fibrosis. A better understanding of pathways leading to CTGF up-regulation may provide new approaches to treating hyperoxia-induced lung fibrosis in premature infants and children.

\section{REFERENCES}

1. Welty SE 2001 Is there a role for antioxidant therapy in bronchopulmonary dysplasia? J Nutr 131:947S-950S

2. Coalson JJ 2003 Pathology of new bronchopulmonary dysplasia. Semin Neonatol 8:73-81

3. Jacob SV, Coates AL, Lands LC, MacNeish CF, Riley SP, Hornby L, Outerbridge EW, Davis GM, Williams RL 1998 Long-term pulmonary sequelae of severe bronchopulmonary dysplasia. J Pediatr 133:193-200

4. Northway WH Jr, Moss RB, Carlisle KB, Parker BR, Popp RL, Pitlick PT, Eichler I, Lamm RL, Brown BW Jr 1990 Late pulmonary sequelae of bronchopulmonary dysplasia. N Engl J Med 323:1793-1799
5. Snider GL, Celli BR, Goldstein RH, O’Brien JJ, Lucey EC 1978 Chronic interstitial pulmonary fibrosis produced in hamsters by endotracheal bleomycin. Am Rey Respir Dis 117:289-297

6. Suki B, Ito S, Stamenovic D, Lutchen KR, Ingenito EP 2005 Biomechanics of the lung parenchyma: critical roles of collagen and mechanical forces. J Appl Physiol 98:1892-1899

7. Dolhnikoff M, Mauad T, Ludwig MS 1999 Extracellular matrix and oscillatory mechanics of rat lung parenchyma in bleomycin-induced fibrosis. Am J Respir Crit Care Med 160:1750-1757

8. Pauluhn J, Baumann M, Hirth-Dietrich C, Rosenbruch M 2001 Rat model of lung fibrosis: comparison of functional, biochemical, and histopathological changes 4 months after single irradiation of the right hemithorax. Toxicology 161:153-163

9. Petrov VV, Fagard RH, Lijnen PJ 2002 Stimulation of collagen production by transforming growth factor- $\beta 1$ during differentiation of cardiac fibroblasts to myofibroblasts. Hypertension 39:258-263

10. Moussad EE, Brigstock DR 2000 Connective tissue growth factor: what's in a name? Mol Genet Metab 71:276-292

11. Bradham DM, Igarashi A, Potter RL, Grotendorst GR 1991 Connective tissue growth factor: a cysteine-rich mitogen secreted by human vascular endothelia 1 cells is related to the SRC-induced immediate early gene product CEF-10. J Cell Biol 114:1285-1294

12. Blom IE, Goldschmeding R, Leask A 2002 Gene regulation of connective tissue growth factor: new target for antifibrotic therapy? Matrix Biol 21:473-482

13. Warner BB, Stuart LA, Papes RA, Wispé JR 1998 Functional and pathological effects of prolonged hyperoxia in neonatal mice. Am J Physiol 275:L110-L117

14. Veness-Meehan KA, Bottone FGJe, Stiles AD 2000 Effects of retinoic acid on airspace development and lung collagen in hyperoxia-exposed newborn rats. Pediatr Res 48:434-444

15. Ozer EA, Kumral A, Ozer E, Yilmaz O, Duman N, Ozkal S, Koroglu T, Ozkan H 2005 Effects of erythropoietin on hyperoxic lung injury in neonatal rats. Pediatr Res 58:38-41

16. Burri PH 1974 The postnatal growth of the rat lung. III. Morphology. Anat Rec 180:77-98

17. Bonikos DS, Bensch KG, Ludwin SK, Northway WH 1975 Oxygen toxicity in the newborn: the effect of prolonged 100 per cent $\mathrm{O} 2$ exposure on the lungs of newborn mice. Lab Invest 32:619-635

18. Frank L, Groseclose E 1982 Oxygen toxicity in newborn rats: the adverse effects of undernutrition. J Appl Physiol 53:1248-1255

19. Han RN, Buch NS, Tseu I, Young J, Christie NA, Frndova H, Lye SJ, Post M, Tanswell AK 1996 Changes in structure, mechanics, and insulin-like growth factorrelated gene expression in the lungs of newborn rats exposed to air or $60 \%$ oxygen. Pediatr Res 39:921-929

20. Kunig AM, Balasubramaniam V, Markham NE, Seedorf G, Gien J, Abman SH 2006 Recombinant human VEGF treatment transiently increases lung edema but enhances lung structure after neonatal hyperoxia. Am J Physiol Lung Cell Mol Physiol 291:L1068-L1078

21. O'Reilly MA 2001 DNA damage and cell cycle checkpoints in hyperoxic lung injury: braking to facilitate repair. Am J Physiol Lung Cell Mol Physiol 281:L291L305

22. Lee J, Reddy R, Barsky L, Weinberg K, Driscoll B 2006 Contribution of proliferation and DNA damage repair to alveolar epithelial type 2 cell recovery from hyperoxia. Am J Physiol Lung Cell Mol Physiol 290:L685-L694

23. Slater AF, Stefan C, Nobel I, van den Dobbelsteen DJ, Orrenius S 1995 Signaling mechanisms and oxidative stress in apoptosis. Toxicol Lett 82-83:149-153

24. Kazzaz JA, Xu J, Palaia TA, Mantell L, Fein AM, Horowitz S 1996 Cellular oxygen toxicity. Oxidant injury without apoptosis. J Biol Chem 271:15182-15186

25. Hargitai B, Szabo V, Hajdu J, Harmath A, Pataki M, Farid P, Papp Z, Szende B 2001 Apoptosis in various organs of preterm infants: histopathologic study of lung, kidney, liver, and brain of ventilated infants. Pediatr Res 50:110-114

26. Adamson IY, Young L, Bowden DH 1988 Relationship of alveolar epithelial injury and repair to the induction of pulmonary fibrosis. Am J Pathol 130:377-383

27. Hagimoto N, Kuwano K, Miyazaki H, Kunitake R, Fujita M, Kawasaki M, Kaneko Y, Hara N 1997 Induction of apoptosis and pulmonary fibrosis in mice in response to ligation of FAS antigen. Am J Respir Cell Mol Biol 17:272-278

28. O'Reilly MA, Staversky RJ, Huyck HL, Watkins RH, LoMonaco MB, D'Angio CT, Baggs RB, Maniscalco WM, Pryhuber GS $2000 \mathrm{Bcl}-2$ family gene expression during severe hyperoxia induce lung injury. Lab Invest 80:1845-1854

29. Howlett CE, Hutchison JS, Veinot JP, Chiu A, Merchant P, Fliss H 1999 Inhaled nitric oxide protects against hyperoxia-induced apoptosis in rat lungs. Am J Physiol 277:L596-L605

30. Grotendorst GR, Okochi H, Hayashi N 1996 A novel transforming growth factor beta response element controls the expression of the connective tissue growth factor gene. Cell Growth Differ 7:469-480

31. Bonniaud P, Martin G, Margetts PJ, Ask K, Gauldie J, Kolb M 2004 Connective tissue growth factor is crucial to inducing a profibrotic environment in "fibrosis resistant" Balb/c mouse lungs. Am J Respir Cell Mol Biol 31:510-516

32. Lasky JA, Ortiz LA, Tonthat B, Hoyle GW, Corti M, Athas G, Lungarella G, Brody A, Friedman M 1998 Connective tissue growth factor mRNA expression is upregulated in bleomycin-induced lung fibrosis. Am J Physiol 275:L365-L371

33. Bonniaud P, Margetts PJ, Kolb M, Haberberger T, Kelly M, Robertson J, Gauldie J 2003 Adenoviral gene transfer of connective tissue growth factor in the lung induces transient fibrosis. Am J Respir Crit Care Med 168:770-778

34. Frazier K, Williams S, Kothapalli D, Klapper H, Grotendorst GR 1996 Stimulation of fibroblast cell growth, matrix production, and granulation tissue formation by connective tissue growth factor. J Invest Dermatol 107:404-411 